Document downloaded from:

http://hdl.handle.net/10251/64706

This paper must be cited as:

Alió Del Barrio, JL.; Chiesa, M.; Gallego Ferrer, G.; Garagorri, N.; Briz, N.; Fernández Delgado, J.; Sancho-Tello Valls, M.... (2015). Biointegration of corneal macroporous membranes based on poly(ethyl acrylate) copolymers in an experimental animal model. Journal of Biomedical Materials Research Part A. 103A(3):1106-1118. doi:10.1002/jbm.a.35249.

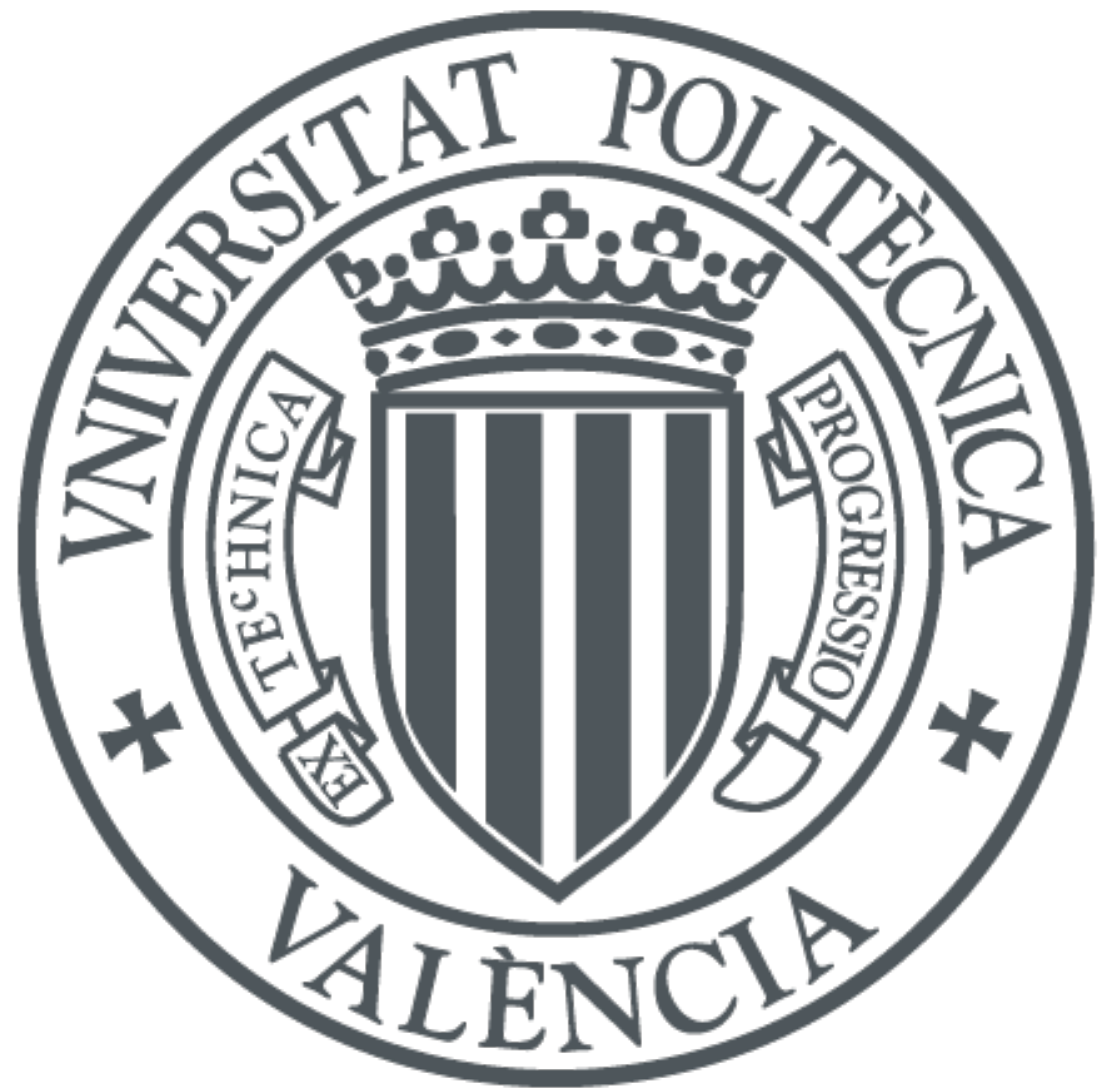

The final publication is available at

http://dx.doi.org/10.1002/jbm.a.35249

Copyright Wiley: 12 months

Additional Information 


\section{Biointegration of corneal macroporous membranes based on poly(ethyl acrylate) copolymers in an experimental animal model.}

Jorge L. Alió del Barrio, $\mathrm{MD}^{1}$, Massimo Chiesa, $\mathrm{PhD}^{2}$, Gloria Gallego Ferrer, $\mathrm{PhD}^{3,4}$, Nerea Garagorri, $\mathrm{PhD}^{4,5}$, Nerea Briz, $\mathrm{PhD}^{4,5}$, Jorge Fernandez-Delgado, $\mathrm{MD}^{6}$, Ignacio García-Tuñón, $\mathrm{PhD}^{2}$, Laurent Bataille, $\mathrm{PhD}^{7}$, Alejandra Rodriguez, $\mathrm{PhD}^{7}$, Francisco Arnalich-Montiel, MD, $\mathrm{PhD}^{1}$, Jose L. Gómez Ribelles, $\mathrm{PhD}^{3,4}$ Carmen M. AntolinosTurpín ${ }^{3}$, Jose A. Gómez-Tejedor, $\mathrm{PhD}^{3}$, Jorge L. Alió, $\mathrm{MD}, \mathrm{PhD}^{7}$, and Maria P. De Miguel, $\mathrm{PhD}^{2 *}$

${ }^{1}$ Department of Ophthalmology, Ramon y Cajal Hospital, Madrid, Spain.

${ }^{2}$ Cell Engineering Laboratory, IdiPAZ, La Paz Hospital Research Institute, Madrid 28046, Spain.

${ }^{3}$ Center for Biomaterials and Tissue Engineering, Polytechnic University of Valencia, 46022 Valencia, Spain.

${ }^{4}$ CIBER de Bioingeniería, Biomateriales y Nanomedicina (CIBER-BBN), Spain

${ }^{5}$ Tecnalia Research \& Innovation, Health Division-Biomaterials Area, Mikeletegi Pasealekua 2, 20009 Donostia-San Sebastian, Spain

${ }^{6}$ Department of Plastic and Reconstructive Surgery, Santa Cristina Hospital and Centrocim, Madrid, Spain.

${ }^{7}$ Vissum Ophthalmological Institute and Miguel Hernandez University, Alicante, Spain.

* Corresponding author.

Address for correspondence and reprints: Maria P De Miguel, Cell Engineering Laboratory, IdiPAZ, La Paz Hospital Research Institute, Paseo Castellana 261, Madrid 28046, Spain. mariapdemiguel@gmail.com. +34912071458.

KEYWORDS: Poly(ethyl acrylate), Adipose derived stem cells, Cornea, Macroporous membranes, Corneal scaffold.

J Biomed Mater Res Part A 2015:103A:1106-1118. DOI: 10.1002/jbm.a.35249 
J Biomed Mater Res Part A 2015:103A:1106-1118.

DOI: $10.1002 / \mathrm{jbm} . \mathrm{a} .35249$

\section{ABSTRACT}

Currently available keratoprosthesis models (non biological corneal substitutes) have a less than $75 \%$ graft survival rate at two years. We aimed at developing a model for keratoprosthesis based on the use of polyethyl acrylate (PEA)-based copolymers, extracellular matrix-protein coating and colonization with adipose-derived mesenchymal stem cells. Human adipose tissue derived mesenchymal stem cells (hADASC) colonization efficiency of seven PEA-based copolymers in combination with four extracellular matrix coatings were evaluated in vitro. Then, macroporous membranes composed of the optimal PEA subtypes and coating proteins were implanted inside rabbit cornea. After a three-month follow-up, the animals were euthanized, and the clinical and histological biointegration of the implanted material were assessed. h-ADASC adhered and survived when cultured in all PEA-based macroporous membranes. The addition of high hydrophilicity to PEA membranes decreased h-ADASC colonization in vitro. PEA based copolymer containing $10 \%$ hydroxyethyl acrylate (PEA-HEA10) or 10\% acrylic acid (PEA-AAc10) monomeric units showed the best cellular colonization rates. Collagen plus keratan sulfate-coated polymers demonstrated enhanced cellular colonization respect to fibronectin, collagen or uncoated PEAs. In vivo implantation of membranes resulted in an extrusion rate of $72 \%$ for PEA, 50\% for PEA-AAc10, but remarkably of $0 \%$ for PEA-HEA10. h-ADASC survival was demonstrated in all the membranes after three months follow-up. A slight reduction in the extrusion rate of h-ADASC colonized materials was observed. No significant differences between the groups with and without h-ADASC were detected respect to transparency or neovascularization. We propose PEA with low hydroxylation as a scaffold for the anchoring ring of future keratoprosthesis. 
J Biomed Mater Res Part A 2015:103A:1106-1118.

DOI: $10.1002 / \mathrm{jbm} . \mathrm{a} .35249$

\section{INTRODUCTION}

Currently available keratoprosthesis models (non biological corneal substitutes) are composed by a central material with optical qualities (usually poly methyl methacrylate -PMMA) surrounded by a second material with anchoring functions to the host tissue and without optical relevance (scaffold or skirt). However, these prostheses have major limitations (a high incidence of glaucoma, retroprosthetic membranes, stromal melting, implant extrusion, etc.), with a less than $75 \%$ graft survival rate at two years and poor long-term visual outcomes due to device-related complications [1-3]. These procedures are therefore only used to treat cases of severe bilateral corneal opacification with high risk of rejection or failure and when other transplantation techniques are not suitable. This situation highlights the need to develop new biomaterials for use as scaffolds for corneal prostheses, which could expand and simplify the surgical techniques that are the only treatment options for some patients.

A number of studies have been published on the subject, in which several corneal cell lines were employed for the colonization of various scaffolds, providing positive results regarding adhesion and cell survival in vitro [4-6]. The cellular component of the corneal stroma is composed primarily of keratocytes, mitotically quiescent cells with flat and dendritic morphology, which secrete collagens and keratan sulfate proteoglycans [7]. The use of autologous human keratocytes has major drawbacks such as damage to the donor cornea, low cell numbers, and inefficient cell subculture [6]. In recent years, research has been conducted looking for of an autologous extraocular source of cells that could be used for tissue-engineered corneas [8,9]. Human adult adipose tissue has been shown to be an ideal source of stem cells that can be used autologously: easy accessibility to the tissue, high cell retrieval efficiency, and the ability of its stem cells (known as human adipose-derived adult stem cells [h-ADASCs]) to differentiate into multiple cell types (keratocytes, osteoblasts, chondroblasts, myoblasts, hepatocytes, neurons, etc.) [6,8]. These cells have also shown immunomodulatory properties in syngeneic, allogeneic and even xenogeneic scenarios [10-12]. A previous study from our group found that h-ADASCs transplanted into damaged rabbit corneas were capable of functionally differentiating into adult corneal keratocytes. The h-ADASCs also produced collagens and proteoglycans in the host corneal stroma themselves; however, the collagen production was insufficient for restoring corneal thickness and transparency [8]. 
Our purpose is to develop a new scaffold model with optimal biointegration with the surrounding corneal stroma that could be used to generate enhanced keratoprosthesis with fewer postoperative complications. The aim of this study was to evaluate the in vivo biocompatibility of thin macroporous membranes made of poly(ethyl acrylate) (PEA)-based copolymer networks produced by a method that combines template techniques to produce the macropores and an anisotropic pore collapse to yield the thin membranes. These scaffolds were seeded or not with h-ADASCs before implantation inside the rabbit cornea.

\section{MATERIALS AND METHODS}

\subsection{Biomaterials}

Seven separate copolymer networks were synthesized by copolymerization of ethyl acrylate (EA 99\% pure; Scharlau, Spain) with hydroxyethyl acrylate (HEA 96\% pure; Aldrich, Spain), acrylic acid (AAc 99\% pure, Scharlau, Spain), or methacrylic acid (MAAc 99\% pure, Scharlau, Spain). The weight ratios of the various copolymers are listed in Table 1 . The copolymers were synthesized as polymer films with round shape of $5 \mathrm{~mm}$ in diameter and presenting a flat smooth surface.

\begin{tabular}{llc}
\hline Reference & & $\begin{array}{c}\text { WCA of } \\
\text { Copolymer Films }\end{array}$ \\
\hline PEA & Poly(ethyl acrylate) homopolymer & $72.3 \pm 0.07$ \\
PEA-HEA10 & Copolymer with $90 \%$ ethyl acrylate and $10 \%$ hydroxyethyl acrylate & $69.7 \pm 0.30$ \\
PEA-HEA20 & Copolymer with $80 \%$ ethyl acrylate and $20 \%$ hydroxyethyl acrylate & $67.9 \pm 0.05$ \\
PEA-AAc10 & Copolymer of $90 \%$ ethyl acrylate and $10 \%$ acrylic acid & $70.5 \pm 0.06$ \\
PEA-MAAc10 & Copolymer of $90 \%$ ethyl acrylate and $10 \%$ methacrylic acid & $71.0 \pm 0.04$ \\
PEA-AAc20 & Copolymer of $80 \%$ ethyl acrylate and $20 \%$ acrylic acid & $60.5 \pm 0.18$ \\
PEA-MAAc20 & Copolymer of $80 \%$ ethyl acrylate and $20 \%$ methacrylic acid & $71.4 \pm 0.05$ \\
\hline
\end{tabular}

Table 1. Nomenclature, composition and reference of PEA and PEA based copolymers used. The water contact angle values measured in polymer films (taken from reference 18) are also listed.

\subsection{Biofunctionalization of PEA and PEA copolymers}

2.2.1 Preparation of fibronectin (FN)-coated surfaces. The FN coatings were performed as described previously [13]. Flat samples of PEA polymers and PEA-based copolymers containing 10 or $20 \mathrm{wt} \%$ hydroxyethyl acrylate were treated with a solution of human plasma FN (Sigma, Spain) dissolved in phosphate saline buffer (PBS) (Sigma, Spain). A volume of $100 \mu \mathrm{l}$ was used to cover the different polymeric disks ( $5 \mathrm{~mm}$ of diameter) for 1 hour ( 30 minutes at $37^{\circ} \mathrm{C}$ and 30 minutes at RT). Finally, disks were washed three times with PBS. FN was covalently cross-linked to disks of different copolymers of EA 
containing 10 or $20 \mathrm{wt} \%$ AAc or MAAc. The carboxylated copolymers were reacted with $2 \mathrm{mM} \mathrm{N}$-(3-dimethylaminopropyl)-N'-ethylcarbodiimide hydrochloride (EDAC purchased in Sigma, Spain) and $5 \mathrm{mM} \mathrm{N}$-hydroxysulfosuccinimide sodium salt (NHS from Sigma, Spain) in 2-(N-Morpholino) ethanesulfonic acid buffer (MES from Sigma, Spain) $\mathrm{pH} 5.5$ for $30 \mathrm{~min}$ in order to converse the carboxylic acid in reactive ester to posterior amidation with free amine groups of FN. After a wash with MES pH 5.5, the disks were reacted with human FN $(0.5 \mathrm{mg} / \mathrm{ml}$, Sigma, Spain) in MES pH 5.5 for $2 \mathrm{~h}$ and then washed once with MES pH 5.5 and twice with PBS.

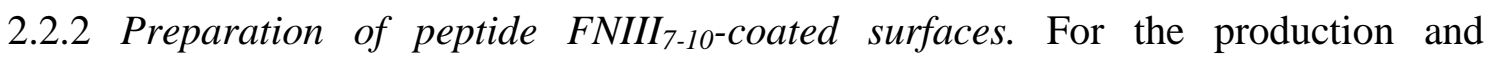
purification of $\mathrm{FNIII}_{7-10}$, the pET-11 plasmid containing the $\mathrm{FNIII}_{7-10}$ sequence was transferred into E. coli B121 (DE3) (Invitrogen, Spain) and expressed as described elsewhere [14]. The expressed proteins were entirely in the supernatant. The protein was precipitated from the bacterial supernatant at $40 \%\left(\mathrm{NH}_{4}\right) \mathrm{SO}_{4}$ saturation (Sigma, Spain), centrifuged at $10,000 \mathrm{~g}$ for $5 \mathrm{~min}$ to pellet out the protein, resuspended in 0.02 M Tris-HCl (pH 7.9) containing $0.02 \%$ sodium azide (Sigma, Spain) and chromatographed on mono Q (Biorad, Spain), where it was eluted with $0.2 \mathrm{M} \mathrm{NaCl}$ (Sigma, Spain). The protein was finally quantified using Bradford reagent; $1.7 \mu \mathrm{g} / \mathrm{ml}$ of FNIII $_{7-10}$ was obtained.

The FNIII $_{7-10}$ surface coating was performed by adsorption on PEA and PEA copolymers containing $10 \%$ and $20 \%$ HEA. The disks were coated with $100 \mu$ of 170 $\mathrm{ng} / \mathrm{ml} \mathrm{FNIII}_{7-10}$ in phosphate saline buffer for $2 \mathrm{~h}$; the disks were then washed with PBS. The coating on PEA copolymers containing 10 or 20 wt\% AAc or MAAc was performed by covalent immobilization. The carboxylated copolymers were combined with $2 \mathrm{mM} N$-(3-dimethylaminopropyl)- $N$ '-ethylcarbodiimide hydrochloride (EDAC; Sigma, Spain) and $5 \mathrm{mM} N$-hydroxysulfosuccinimide sodium salt (NHS; Sigma, Spain) in a pH 5.5 2-(N-Morpholino) ethane sulfonic acid buffer (MES; Sigma, Spain) for 30 min to convert the carboxylic acids in the reactive ester for the subsequent reaction with the free amine groups of $\mathrm{FNIII}_{7-10}$. After a wash with MES at $\mathrm{pH} 5.5$, and a reaction with human FNIII $_{7-10}\left(170 \mathrm{ng} / \mathrm{ml}\right.$; Sigma, Spain) in MES pH 5.5 for $2 \mathrm{~h}$ at $37^{\circ} \mathrm{C}$, the disks were washed once with MES pH 5.5 and twice with PBS.

2.2.3 Preparation of collagen and collagen-keratan sulfate (KSPG) coated surfaces. PEA and PEA copolymer containing $10 \%$ of hydroxyethyl acrylate (HEA) and 10\% acrylic acid (Acc) were incubated overnight in a cold solution of collagen in acidic 
conditions at $4^{\circ} \mathrm{C}$. The carboxylated copolymer were previously reacted with $2 \mathrm{mM} \mathrm{N}$ (3-dimethylaminopropyl)- $N$ '-ethylcarbodiimide hydrochloride (EDAC purchased from Sigma, Spain) and $5 \mathrm{mM} N$-hydroxysulfosuccinimide sodium salt (NHS from Sigma, Spain) in $\mathrm{pH} 5.5$ 2-(N-Morpholino) ethanesulfonic acid buffer (MES from Sigma, Spain) for $30 \mathrm{~min}$ in order to converse the carboxylic acid in reactive ester to posterior amidation with free amine groups of collagen.

Following the overnight incubation, the collagen solution was removed and collagen fibrillation was conducted with phosphate buffer at $37^{\circ} \mathrm{C}$. The crosslinking process was performed to improve the biostability of the coating; the disks were incubated in MES buffer with EDAC/NHS at $\mathrm{pH}$ 5.5. After crosslinking, the disks were washed with $1 \mathrm{M}$ $\mathrm{Na}_{2} \mathrm{HPO}_{4}$ and distilled water. The collagen-coated disks were freeze-dried. The incorporation of KSPG to the collagen was performed during the crosslinking process (40 $\mu \mathrm{g}$ of $\mathrm{KSPG} / \mathrm{ml}$ of MES/EDAC/NHS). Also, macroporous membranes of poly ethyl acrylate and copolymer of EA containing 10\% HEA, and copolymer of EA containing $10 \%$ AAc were coated with collagen and KSPG for the in vivo assays.

\subsubsection{Characterization of the coating efficiency by enzyme-linked immunosorbent assay}

(ELISA). The biocoated copolymer disks were blocked with $2 \%$ bovine serum albumin in PBS for $2 \mathrm{~h}$ at $37^{\circ} \mathrm{C}$ and then washed twice with PBS. The primary antibodies and dilutions employed were polyclonal anti-human fibronectin antibody (Sigma) at 1:50 dilution; FNIII $_{7-10}$ (HFN7.1 antibody) (Abcam) at 1:260 dilution; collagen antibody (collagen I antibody [COL-1]) (Abcam ab90395) at 1:500 dilution; and mouse antikeratan sulfate monoclonal antibody (Acris, BM553) at 1:900 dilution. These antibodies were incubated for $2 \mathrm{~h}$ at $37^{\circ} \mathrm{C}$. The secondary antibodies were conjugated with horse radish peroxidase [HRP]: rabbit polyclonal secondary antibody to mouse $\operatorname{IgG}-\mathrm{H} \& \mathrm{~L}$ (HRP) (ab6728), was obtained from Abcam, and anti-rabbit IgG-peroxidase antibody produced in goat was obtained from Sigma. After intensive rinsing with phosphatebuffered saline with Tween 20 (PBST), the secondary HRP-conjugated antibodies were added at 1:45 dilution when detectin fibronectin, at 1:83 dilution when detectingFNIII 10 , and at 1:130 dilution when detecting collagen and KSPG. Incubation was conducted for $1 \mathrm{~h}$ at $37^{\circ} \mathrm{C}$. The surfaces were rinsed with PBST, followed by the addition of 3,3',5,5'-tetramethylbenzidine substrate solution at RT for $15 \mathrm{~min}$. The reaction was stopped by transferring part of the dye solution to a 96-well plate (Corning, USA) with a $2 \mathrm{~N} \mathrm{H}_{2} \mathrm{SO}$ stop solution.. The optical density was measured at $450 \mathrm{~nm}$ with a Power 
Wave XS reader (BioTek Instruments Inc., Winooski, VT, USA). Three disks were analyzed for each material, and each antibody and copolymer without coating were studied as a reference, except for $\mathrm{FN}$, in which nine disks were analyzed. Nine replicates were evaluated for $\mathrm{FN}$, three for $\mathrm{FNIII}_{7-10}$, three for collagen and collagen with KSPG on polymer films, and twelve for collagen and collagen with KSPG on macroporous polymer membranes.

2.2.5 Coating visualization by scanning electron microscopy. The samples were prepared for structural analysis with gold deposition in a sputter coater (Polaron SC762, VGMicrotech, East Grinstead, UK) at $25 \mathrm{~mA}$ for $30 \mathrm{~s}$. The metal coating on the surface allowed for sample analysis under high vacuum in an SEM (JEOL JSM 5910 LV, Tokyo, Japan).

\subsection{Isolation of h-ADASCs}

Lipoaspirate from a female donor patient undergoing elective liposuction was obtained by a plastic surgeon (J. F-D). The isolation protocols and usage of the tissue were approved by the institutional review board of the hospital and stored in the Biobank of La Paz Hospital (Madrid, Spain). Oral and written consent form was obtained from the patients. Active infection by HIV, hepatitis C virus, and syphilis was ruled out by serological analyses. The lipoaspirate obtained was washed extensively with phosphatebuffered saline, digested, and processed as reported previously [15]. The pellet obtained was cultured in a noninductive medium consisting of Dulbecco's modified Eagle's medium (Gibco-BRL, Grand Island, NY, USA) containing $1 \mathrm{mM}$ sodium pyruvate and $2 \mathrm{mM}$ glutamine (Sigma-Aldrich, St. Louis, MO, USA), 10\% fetal bovine serum (Whittaker, Walkersville, MD, USA), and $100 \mathrm{U} / \mathrm{ml}$ penicillin G and streptomycin solution (Gibco-BRL). This protocol has been shown in a previous study by our group to be effective in isolating h-ADASCs capable of multipotent lineage differentiation [8].

\section{4 h-ADASC colonization of PEA and PEA copolymer films in vitro}

2.4.1 Evaluation of the biophysical characteristics of the biomaterials in culture. The various biomaterials (without biofunctionalization) were freeze-dried and sterilized. Then they were pre-incubated in medium for $24 \mathrm{~h}$ to allow hydration and stabilization. The medium contained 10\% FBS. Hydrophilicity, pH, stability, and transparency were assessed. 
2.4.2 Cell culture. The biomaterials, which presented as circular prosthetic discs measuring $6 \mathrm{~mm}$ in diameter and $100 \mu \mathrm{m}$ thick, were inserted in 96-well plates (Corning, NY, USA), washed twice with PBS (Gibco-BRL) and preincubated in culture medium. After $24 \mathrm{~h}, 100,000$ cells in $100 \mu \mathrm{l}$ of medium were seeded onto the biomaterial.

2.4.3 Cell survival on coated polymers. First, comparison of cellular survival on the various biomaterials, alone or covered with coatings, was performed by counting the cells one and four weeks after seeding. Cells were counted with 4',6-diamidino-2phenylindole (DAPI) staining in vivo. DAPI (Sigma) was added at a final concentration of $5 \mathrm{ng} / \mathrm{ml}$ to culture medium, and cells were incubated for $15 \mathrm{~min}$ at $37^{\circ} \mathrm{C}$. After two washes with PBS, fresh medium was added to the cells. Random field pictures of the stained nuclei were then taken with the microscope using a 20x objective. At least five different fields were counted to calculate the total number of cells. Pictures were taken with a Nikon camera (Nikon Corporation, Tokyo, Japan) mounted on a Zeiss inverted microscope and processed with the software Nis-elements (Nikon). The experiment was repeated three times, and the statistical significance was analyzed using the Student- $t$ test with Bonferroni modification. Significance was considered at $\mathrm{p}<0.05$.

Cell colonization was also performed by trypsinizing the biomaterials for $5 \mathrm{~min}$, resuspending the cells, staining them with trypan blue at $0.4 \%$ (Sigma) for $1 \mathrm{~min}$ and counting live cells under an inverted microscope in a hemocytometer. Same number of cells was counted using both methods, so DAPI staining was used afterwards to be able to use the colonized biomaterials for further analysis.

\subsection{PEA macroporous membrane preparation and characterization}

To increase adherence and improve cellular colonization of the biomaterials, macroporous membranes were prepared with a template technique [16]. Templates were prepared by sintering poly(methyl methacrylate) (PMMA) microspheres (Colacryl DP 300; Lucite International, UK) with diameter between 90 and $120 \mu \mathrm{m}$. The porogen microspheres were placed in a metal mold and subjected to successive compressions at $150^{\circ} \mathrm{C}$ in the hot press to obtain the template in sheet form, with a suitable interconnection of PMMA particles. Monomer mixtures of varying compositions containing $1 \mathrm{wt} \%$ ethyleneglycol dimethacrylate (EGDMA 99\% pure; Aldrich, Spain) as cross-linker and $0.5 \mathrm{wt} \%$ benzoin ( $98 \%$ pure, Scharlau, Spain) as photo initiator were 
injected into the voids of the template. The mixtures were then polymerized at room temperature under ultraviolet (UV) light and post-cured at $90^{\circ} \mathrm{C}$ for $24 \mathrm{~h}$. The resulting plates were washed for $24 \mathrm{~h}$ to remove the porogen, using acetone as the solvent. The acetone was evaporated in vacuum, controlling pore collapse, resulting in a $100 \mu \mathrm{m}$ thick porous membrane. Disks $5 \mathrm{~mm}$ in diameter were cut to be implanted in the rabbits. Flat substrates were polymerized as explained above for the macroporous membranes. Mixtures of the co-monomers in the desired ratios, with $1 \mathrm{wt} \%$ EGDMA and $0.5 \mathrm{wt} \%$ benzoin, were inserted into transparent molds. Polymerization was then conducted at room temperature under UV light, producing copolymer plates around $0.5 \mathrm{~mm}$ thick. This was followed by a post-curing treatment at $90^{\circ} \mathrm{C}$ for $24 \mathrm{~h}$ in order to reach full monomer conversion. The plates were then immersed in boiling ethanol for $24 \mathrm{~h}$ to extract any residual low molecular weight substances from the samples. Next day, they were dried in room conditions for $48 \mathrm{~h}$ finally in a vacuum at $60^{\circ} \mathrm{C}$ until a constant weight was achieved.

2.5.1 Microstructural characterization of macroporous membranes. The microstructure of the macroporous membranes was examined by scanning electron microscopy (SEM) using a JEOL JSM 6300 microscope (Japan) at an accelerating voltage of $10 \mathrm{kV}$. The samples were metalized with a gold coating for $90 \mathrm{~s}$ to make the surface of the samples conductive. The porous depth in the macroporous membranes was measured by confocal laser scanning microscopy, using a Nikon C1 microscope (Japan).

2.5.2 Physical and mechanical characterization of macroporous membranes. The water contact angle (WCA) at the surface of the macroporous membranes was determined using the Data Physics OCA 20 (Germany) by measuring the static contact angle of a 10 $\mu l$ drop of water over the solid surface. The results are the average of over six measurements. The mechanical properties of the macroporous membranes were analyzed by testing the resistance to tearing [17]. Tearing strength was measured using a Microtest Electromechanical machine, SCM 3000095 with a $15 \mathrm{~N}$ force transducer. The macroporous membranes with dimensions $30 \times 10 \times 0.1 \mathrm{~mm}^{3}$ were drilled using a needle at both ends. Two suture threads (nylon 10/0) were gone through the holes and a tensile mode strain-rate program at a speed of $10 \mathrm{~mm} / \mathrm{min}$ was performed. Maximum tearing strength at failure was measured, the results were the average of five specimens, and are expressed as mean $\pm \mathrm{SD}$.

\subsection{Implantation of macroporous membranes into rabbit corneas}


Based on the cell survival ability analysis and the biophysical properties, the optimal biomaterials were selected for the in vivo assay. Animal studies were performed following guidelines of the Animal Research Committees at Vissum Ophthalmological Institute of Alicante (Spain) and La Paz Hospital (Spain), and in accordance with the standards of the Association for Research in Vision and Ophthalmology (ARVO) for animal experimentation (ARVO Statement for the Use of Animals in Ophthalmic and Vision Research). To evaluate the biointegration and biosafety of the macroporous membranes transplanted into the rabbit corneas, a controlled triple-masked experiment was performed for each selected biomaterial, with a total of 30 adult New Zealand white rabbits (Granja San Bernardo, Navarra, Spain).

Prior to the in vitro cell seeding of the implants for the in vivo experiment, h-ADASCs were incubated with a 1:200 dilution of fluorescent dialkylcarbocyanine solution Vybrant chloromethylbenzamide (Vybrant CM-DiI) (Molecular Probes, Eugene, OR, USA) in D-PBS for $10 \mathrm{~min}$ and then washed three times in PBS. In this way, all intracytoplasmic membranes (the organelles), except the plasma and nuclear membranes, were fluorescently labeled, and cells could be easily identified under fluorescence optics during the postmortem analysis.

2.6.1 Surgical procedure and postsurgical treatment. The animals were anesthetized with a combination of intramuscular ketamine $(35 \mathrm{mg} / \mathrm{kg})$ and xylazine $(10 \mathrm{mg} / \mathrm{kg})$. The rabbits were placed under an operating microscope and a $5 \mathrm{~mm}$ long and $200 \mu \mathrm{m}$ deep superior paralimbal incision was performed with a $45^{\circ}$ blade. A $7 \mathrm{~mm}$ diameter corneal half-depth intrastromal pocket was then created in the central cornea using a minicrescent blade (Sharptome ${ }^{\mathrm{TM}}$, Sharpoint) to allow space for the macroporous membranes, which were placed unfolded and centered inside the cornea. The incision was then closed with two interrupted 10-0 nylon sutures. Topical ciprofloxacin $0.3 \%$, cyclopentolate hydrochloride $0.5 \%$, and subcutaneous buprenorphine were applied at the end of the surgery and two times a day during four days. Only one eye of each animal (left eye) was used for the experiment. Half of the implants (15 eyes) were hADASC colonized implants and the other half were macroporous membranes without hADASC colonization. For negative mock controls, the contralateral eyes (right eye) were treated using the same procedure, but without the insertion of an implant, or was an untouched control eye.. 
J Biomed Mater Res Part A 2015:103A:1106-1118.

DOI: $10.1002 / \mathrm{jbm} . \mathrm{a} .35249$

\subsubsection{Clinical observation.}

Each treated eye was examined under the microscope while the animals were under general anesthesia (as described above) two, four, eight and 12 weeks after surgery. The examination sought corneal inflammation, transparency $(\mathrm{T})$, neovascularization $(\mathrm{N})$, or any other ocular surface or anterior chamber complication. The cornea is an avascular tissue which transparency is critical for the vision as it permits the proper transmission of the light and its refraction to the retina. The presence of scar tissue or neovessels over or within the cornea compromise its transparency and therefore the visual function of the eye. Neovascularization was evaluated by an external expert ophthalmologist on a masked basis, on a scale of 0 to 3 according to severity (0: absence; 1: peripheral and mild; 2: peripheral and moderate; 3: severe and affecting the central cornea). Corneal transparency was graded on a scale of 1 to 4 (1: transparent but visible implant; 2: mild haze; 3: moderate haze; 4: severe opacification making it difficult to observe the eye's internal structures). The statistical analysis was performed with the non parametric Mann-Whitney test with Bonferroni modification. Significance was considered at $\mathrm{p}<0.05$.

2.6.3 Tissue procurement. Rabbits were euthanized 12 weeks after surgery by an intravenous administration of T-61 euthanasia solution, a combination of embutramide, mebezonium iodide, and tetracaine hydrochloride. The eyes were enucleated, formalinfixed, and paraffin-embedded.

2.6.4 Histological examination and localization of h-ADASCs in the stroma. Several sections of each cornea were stained with hematoxylin-eosin and Masson trichrome for light microscopy examination. The CM-DiI-labeled h-ADASCs cells were located using an epifluorescence microscope.

\section{RESULTS}

3.1 Evaluation of the biophysical characteristics of the biomaterials. After $24 \mathrm{~h}$ in culture medium, the biomaterials PEA-AAc20 and PEA-MAAc20 had visibly increased in size, most probably due to hydration. The $\mathrm{pH}$ of the medium containing biomaterials PEA-AAc10, PEA-MAAc10, PEA-AAc20, and PEA-MAAc20 acidified (Table 1). Biomaterials PEA-MAAc10, PEA-AAc20, and PEA-MAAc20 were opaque and 
J Biomed Mater Res Part A 2015:103A:1106-1118.

DOI: $10.1002 / \mathrm{jbm} . \mathrm{a} .35249$

therefore difficult to observe under the microscope (Table 1). Based on these results, PEA-MAAc10, PEA-AAc20, and PEA-MAAc20 were discarded from further analysis.

\subsection{Biofunctionalization of PEA and PEA copolymers}

Using ELISA, efficient fibronectin adsorption onto the PEA and PEA copolymer membrane surfaces was observed. From the undiscarded materials, PEA, PEA-HEA10 and PEA-AAc10 showed the highest levels of this protein per $\mathrm{cm}^{2}$ of membrane (Figure $1 \mathrm{~A})$.

Peptide FNIII $_{7-10}$ adsorption was less effective, with low levels of this protein found over the membranes (Figure 1B).

B

A

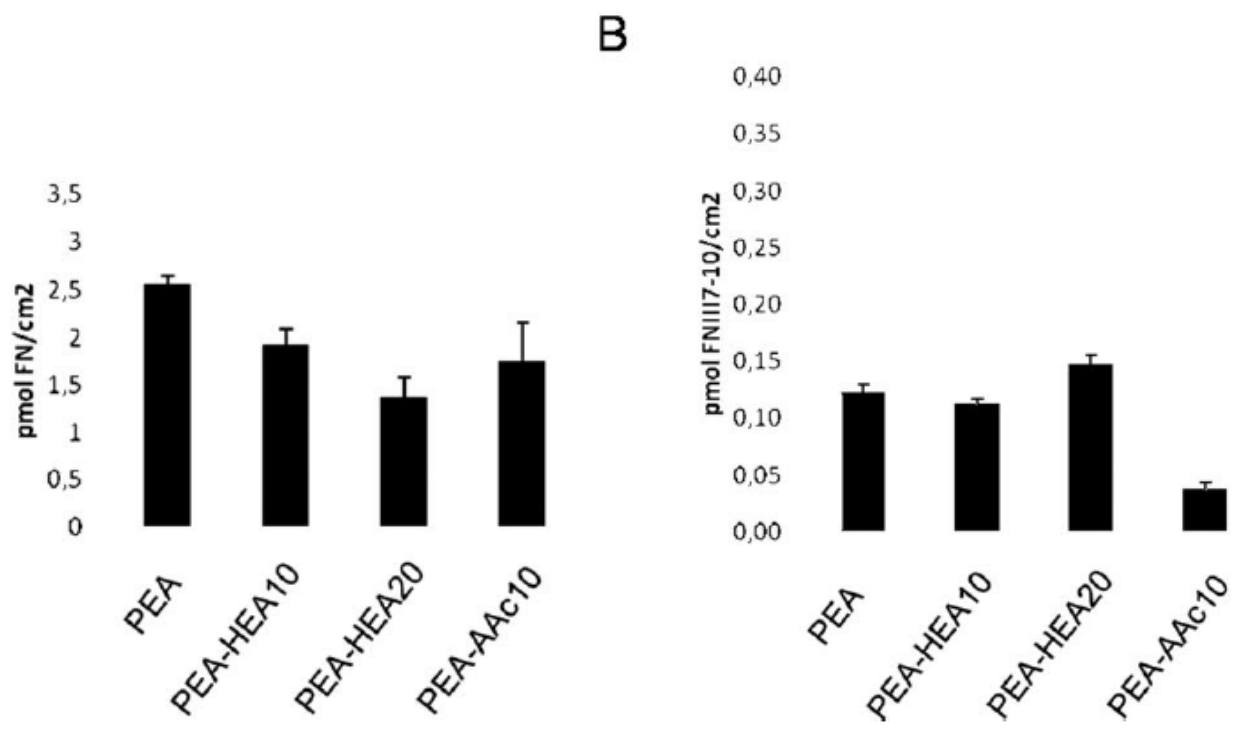

Figure 1. Efficiency of coating adsorption onto the PEA and PEA copolymer membrane surfaces assessed by ELISA. A: Fibronectin coating. PEA and PEA-HEA10 showed the highest levels of this protein per $\mathrm{cm}^{2}$. B: Peptide $\mathrm{FNIII}_{7-10}$ coating adsorption was less effective, with low levels of this protein found over the membranes.

Out of the selected materials, PEA and PEA-HEA10 polymer films showed the most efficient adsorption of collagen and collagen-KSPG onto their surface, whereas PEAAAc10 did not (Figures 2A, B). 


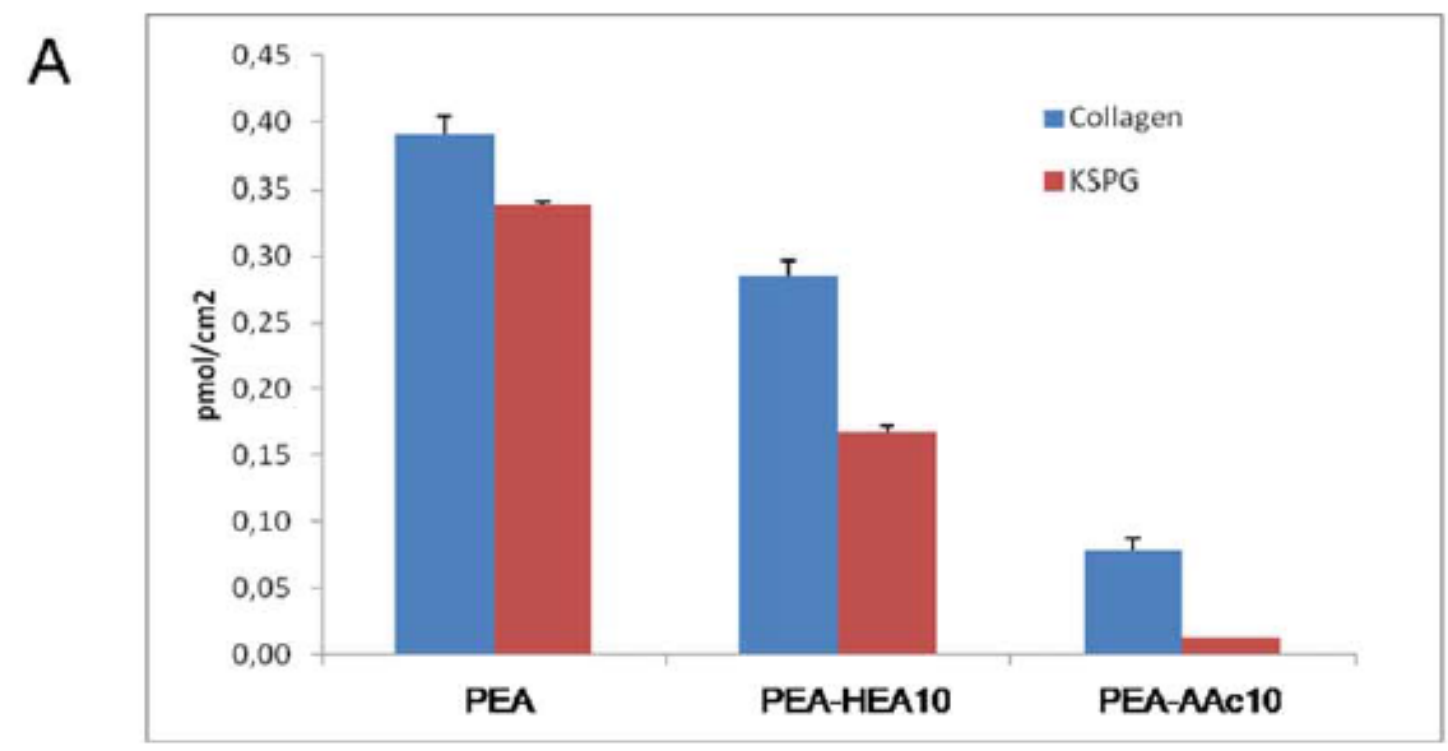

B

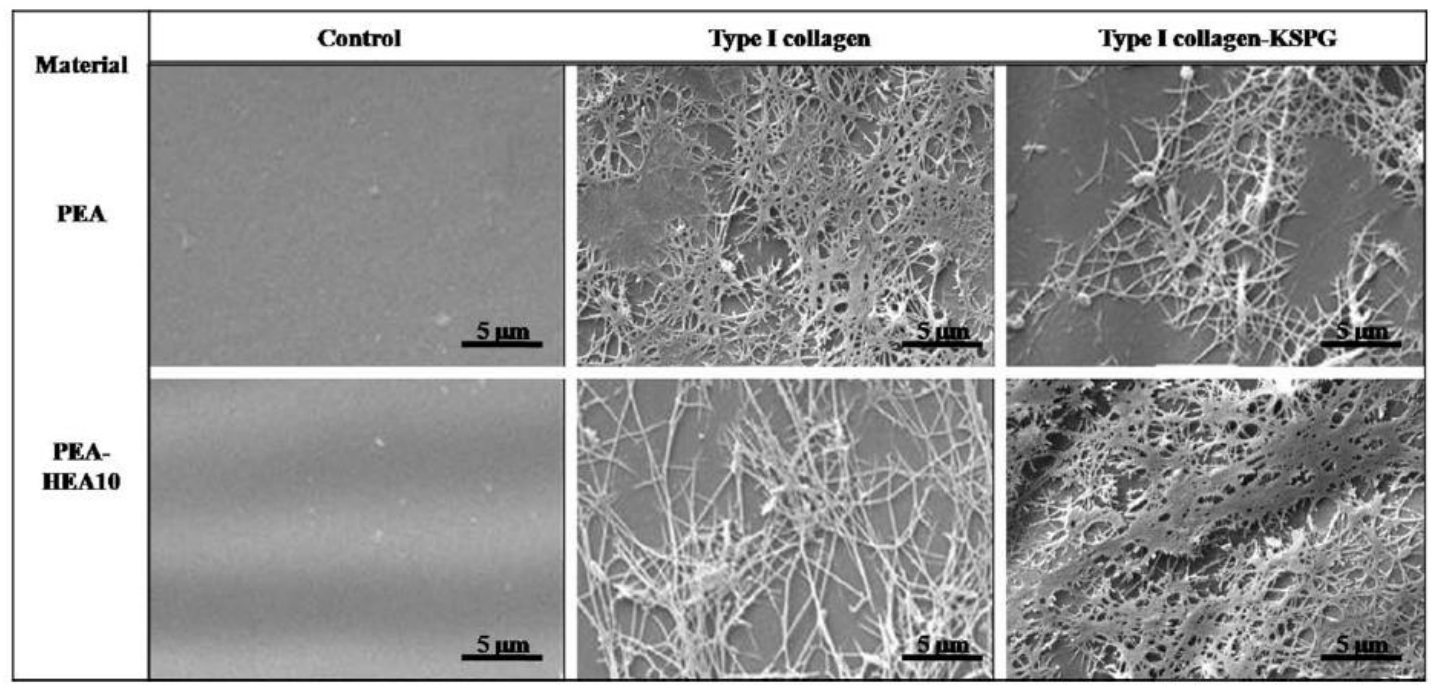

Figure 2. A: Efficiency of coating adsorption onto the PEA and PEA copolymer film surfaces assessed by ELISA with collagen and collagen-KSPG. B: Examples of SEM images of PEA and PEA-HEA10 film polymers with collagen and collagen-KSPG-coated surfaces (scale bar $5 \mu \mathrm{m}$ ).

\section{3 h-ADASC colonization of PEA and PEA copolymers in vitro}

3.3.1 Fibronectin-coated PEA and PEA copolymers. The presence of fibronectin did not significantly increase cellular colonization in any of the biomaterials. In the short-term (one week, Figure 3A), the PEA and PEA-HEA10 samples provided better cellular survival, as did the PEA-AAc20 sample. In the latter case, however, normal cell morphology was not maintained. After four weeks of cell culture, a tendency was observed in a number of cases for the cells to migrate outside the biomaterial (data not 
J Biomed Mater Res Part A 2015:103A:1106-1118.

DOI: $10.1002 / \mathrm{jbm} . \mathrm{a} .35249$

shown). The PEA, PEA-HEA10 and PEA-AAc10 samples once again demonstrated better cell survival on the raw material (Figure 3B).

Based on these results, the PEA-HEA20 biomaterial was excluded from further experiments, and consequently, PEA and PEA-HEA10 were selected for the next in vitro assays due to their more favorable cellular survival ability combined with their optimal biophysical properties.

A



PEA subtype
B

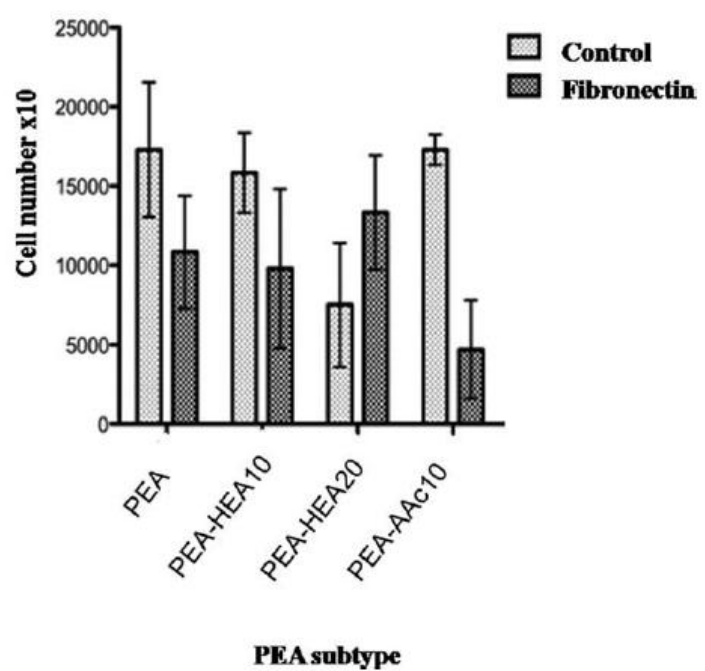

Figure 3. Cell survival at 1 week (A, cell number) and 4 weeks (B, cell number $\times 10^{1}$ ) after the cell seeding of each PEA biomaterial with and without fibronectin coating (mean and SD). No statistically significant differences were observed.

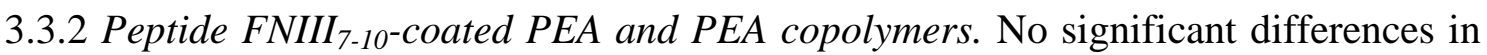
terms of cell survival were observed between the biomaterials with $\mathrm{FNIII}_{7-10}$ coating and those without $\mathrm{FNIII}_{7-10}$ coating (Figure 4). 
A

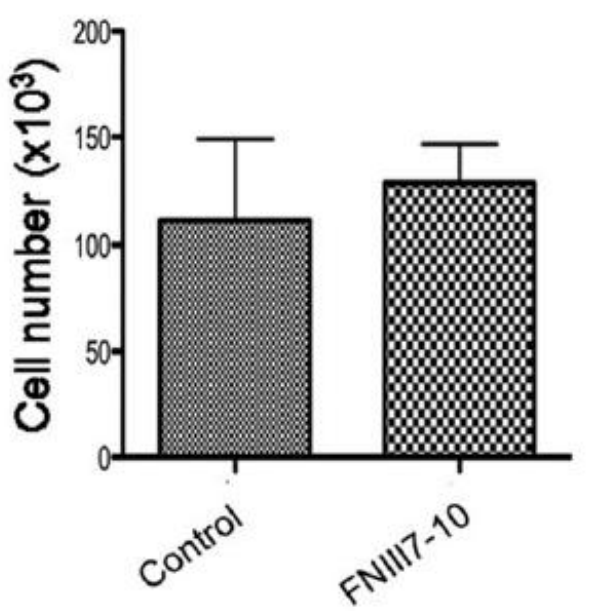

PEA
B

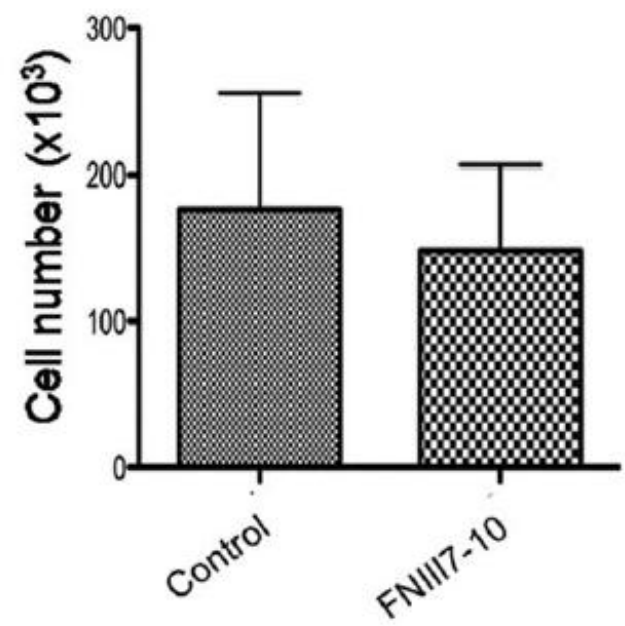

PEA-HEA10

Figure 4. Cell survival at 1 week after the cell seeding PEA (A) and PEA-HEA10 (B) with and without FNIII $_{7-10}$ peptide coating (mean and SD). No statistically significant differences were observed.

3.3.3 Collagen and collagen-keratan sulfate-coated PEA and PEA copolymers. No significant differences were observed with collagen coating alone (Figure 5). However, surfaces coated with collagen-KSPG had significantly improved cell survival in both PEA and PEA-HEA10. Based on this data, the collagen-KSPG coating was selected for the in vivo assay.

A



B

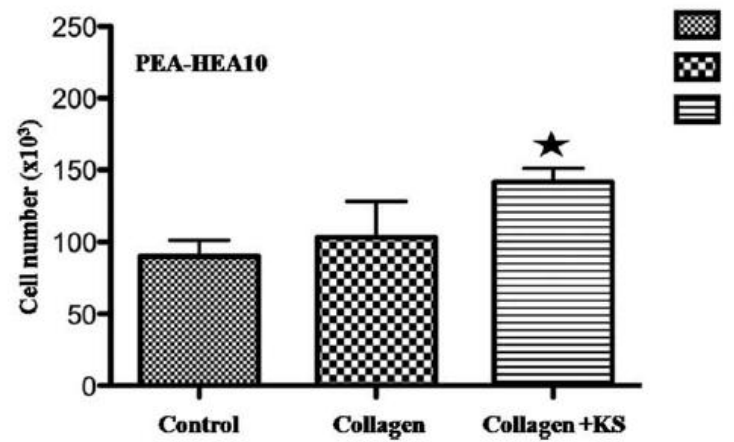

Figure 5. Cell count (cell number $\times 10^{3}$ ) 1 week after the seeding of PEA (A) and PEA-HEA10 (B) with and without collagen or collagen-KSPG covering (mean and SD). Stars: significance at $\mathrm{p}<0.05$ ).

\subsection{Morphology of macroporous membranes}


To further increase adherence and improve cellular colonization of the biomaterials, macroporous membranes were prepared as described in the materials and methods section. Polymerization in the empty volume of the template produced a wellinterconnected structure in the PEA-based copolymer network. Plates approximately 2 $\mathrm{mm}$ thick were produced in this fashion. When the plate was immersed in acetone after the polymerization, the template dissolved. The copolymer network is insoluble due to covalent crosslinking between polymer chains but absorbs a significant amount of acetone. The result was a swollen macroporous structure in which acetone filled the macropores. Solvent evaporation caused the collapse of the pore structure because the swollen copolymer in acetone is very soft. Contraction of the structure was anisotropic, with a significant collapse in the thickness and a moderate collapse on the surface. The result was a thin membrane, approximately $100 \mu \mathrm{m}$ thick, from which the laminas used in the study were cut.

Figure 6 shows SEM images of the pore architectures of PEA (a), PEA-HEA10 (b) and PEA-AAc10 (c) macroporous membranes. It can be seen in Figure 6a that the PEA scaffold had a very well-connected pore structure, with pore size in the horizontal plane between 50 and $200 \mu \mathrm{m}$. Since the templates were used to produce membranes of all the compositions, the initial state before acetone evaporation was quite similar in all membranes; nevertheless, pore collapse depended on composition due to the varying acetone adsorption capacity and viscoelastic properties of the various copolymers. As a consequence, pore architecture was slightly different in the various membranes (Figure 6). While pores were well interconnected in the case of PEA homopolymer and copolymer containing HEA (Figures $6 \mathrm{a}$ and $6 \mathrm{~b}$, respectively), copolymer containing AAc showed a certain tendency to aggregate, producing less permeable structures (Figure 6c).


Figure 6. Examples of SEM images of macroporous membranes transplanted in the in vivo model: a) PEA b) PEA-HEA10 c) PEA-AAc10 (scale bar $200 \mu \mathrm{m}$ ). 
To further analyze the pore structure, the pore depth was measured with confocal microscopy. Pore depth was measured at various points and the mean values are listed in Table 3. These values show that membranes presented a rough surface able to host seeded cells and had a large specific surface for cell and tissue attachment. Pore depth increased in the copolymers with respect to the PEA scaffold (Table 3) due to their increasing capacity to absorb water during solvent exchange from acetone to water.

\begin{tabular}{lcc}
\hline & Pore Depth $(\mu \mathrm{m})$ & $\begin{array}{c}\text { Water Contact } \\
\text { Angle (Degree) }\end{array}$ \\
\hline PEA & $16.5 \pm 2.0$ & $89.45 \pm 0.09$ \\
PEA-HEA10 & $25 \pm 15$ & $84.52 \pm 0.03$ \\
PEA-AAc10 & $80 \pm 20$ & $77.18 \pm 0.18$ \\
\hline
\end{tabular}

Table 2. Pore depth and water contact angle (WCA) for PEA, PEA-HEA10 and PEA-AAc10 macroporous membranes.

\begin{tabular}{lcll}
\hline Reference & $\begin{array}{c}\mathrm{pH} \text { of } \\
\text { the Medium }\end{array}$ & \multicolumn{1}{c}{ Size } & Transparency \\
\hline PEA & 7.5 & Stable & Yes \\
PEA-HEA 10 & 7.5 & Stable & Yes \\
PEA-HEA20 & 7.5 & Stable & Yes \\
PEA-AAc10 & 7.1 & Stable & Yes \\
PEA-MAAc10 & 6.8 & Stable & No \\
PEA-AAc20 & 6.8 & Increased & No \\
PEA-MAAc20 & 6.7 & Increased & No \\
\hline
\end{tabular}

Table 3. Biophysical features of PEA and PEA copolymer biomaterials in culture media.

\subsubsection{Physical and mechanical characterization of macroporous membranes. Water} contact angle shows that PEA is a significantly hydrophobic polymer, but the WCA decreased significantly when $10 \mathrm{wt} \%$ HEA or AAc was inserted into the copolymer chains (Table 3). However, the values found in the porous membranes were higher than those previously reported for flat surfaces (approximately $17^{\circ}$ in the case of PEA and $7^{\circ}$ in the most hydrophilic samples) [18 and Table 2]. This increase in the hydrophobic character could be due to the surface roughness of the macroporous membranes, which is associated with the resistance of drop penetration in the voids of the scaffolds. The 
J Biomed Mater Res Part A 2015:103A:1106-1118.

DOI: $10.1002 / j b m . a .35249$

necessary strength to move the thread at a constant rate until breakage of the sample was measured. The maximum force was $0.07 \pm 0.01 \mathrm{~N}$ in PEA, $0.170 \pm 0.030 \mathrm{~N}$ in PEAHEA10 and 0.269 $\pm 0.034 \mathrm{~N}$ in PEA-AAc10 macroporous membranes. In all the samples these value is significantly higher than the required resistance for surgical suture [17]. Figure 7 shows an example of the results of tearing stress experiments for the PEAHEA10 membrane.

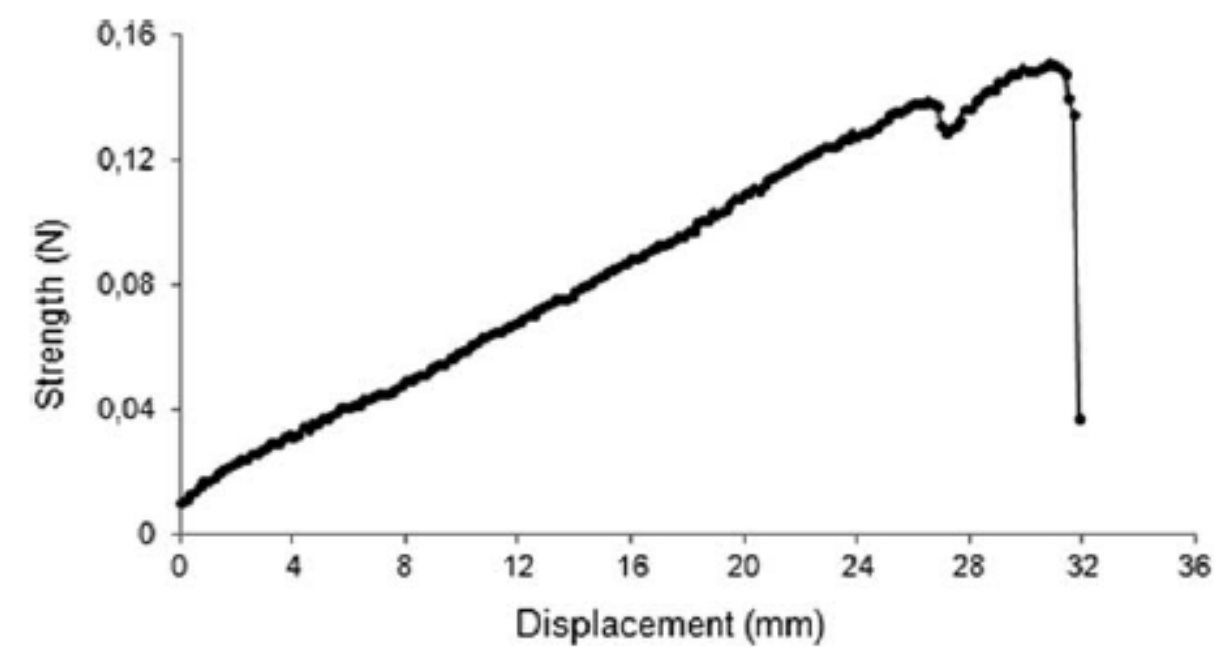

Figure 7. Tearing strength measured in PEA-HEA10 macroporous membrane.

When characterizing the efficiency of collagen and collagen-KSPG coating on the macroporous membranes, it was observed that porous polymers presented a very low adsorption of collagen alone but high levels of collagen-KSPG per $\mathrm{cm}^{2}$ of membrane and at similar amounts in the three biomaterials tested (Figure 8). 


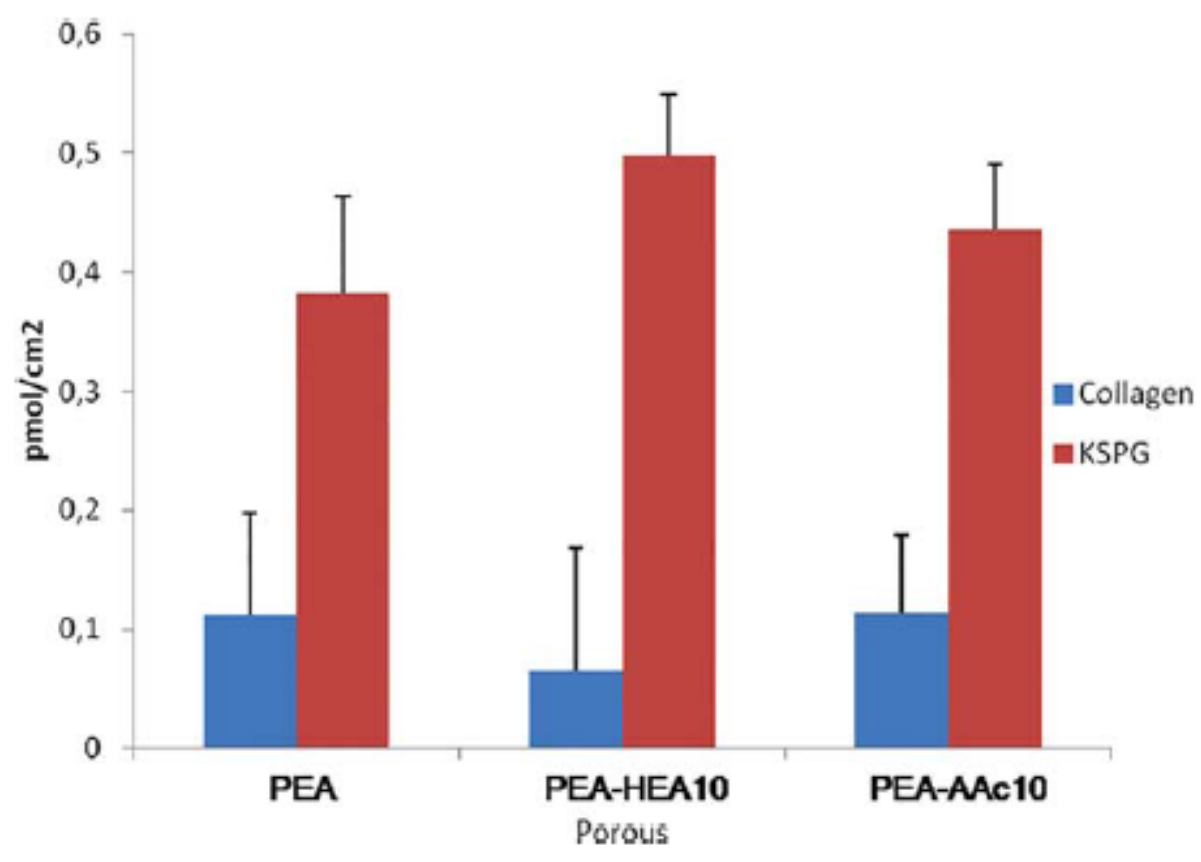

Figure 8. Efficiency of coating adsorption with collagen and collagen-KSPG. assessed by ELISA, onto the PEA and PEA copolymer macroporous membrane surfaces transplanted in the in vivo model.

\subsection{Implantation of macroporous membranes into rabbit corneas}

\subsubsection{Surgery and clinical observation}

Macroporous PEA membranes with collagen-KSPG coating, with or without cellular colonization, were selected for the first in vivo assay. Nine control mock eyes (pockets without macroporous membranes) and 18 experimental eyes (pockets with macroporous membranes) were performed (nine with h-ADASCs and nine without h-ADASCs). The remaining nine eyes were left untouched additional control eyes.

3.5.1.1 PEA macroporous membranes. The macroporous membranes had a transparent and granular appearance and generated a central opacity grade of 1 (T1) from the time of their implantation. Of the 18 PEA-implanted eyes, 13 were extruded (72\%), most of them occurring within the first two months (Figure 9C). Many of these cases had previously developed early, sterile persistent corneal ulcers. In most non extruded cases, transparency remained stable during the entire follow-up, and corneal neovascularization was mild or moderate, peripheral and always above the surgical incision (Figure 9A). One case did not present neovascularization and two cases developed severe and progressive opacification and neovascularization of the implant from the second month of monitoring (Figure 9B). The peripheral cornea remained 
intact and free from vessels and scars throughout the study. There was no clinically relevant ocular inflammation related to the implant.
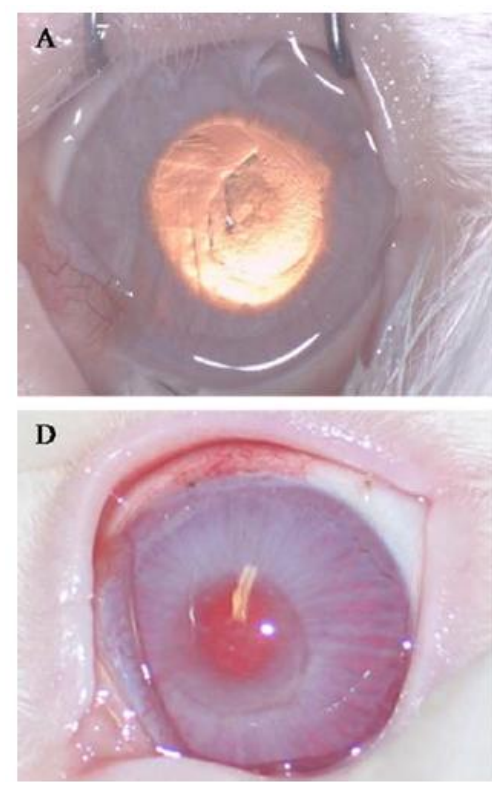
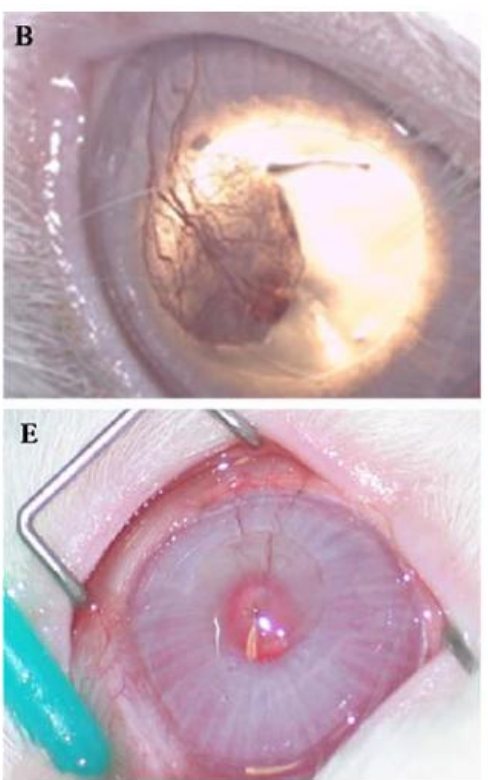



F



Figure 9. Examples of clinical results (magnification $2 \mathrm{X}$ ) obtained at the moment of euthanasia after 3 months with PEA (A, B, C-extrusion), PEA-HEA10 (D, E) and PEA-AAc10 (F). Note opacification of the implant of biomaterials PEA (A,B, C) and PEA-AAc10 (F), transparency of PEA-HEA10 (D, E), and neovascularization with PEA-AAc10 (F).

Based on these results, we decided to continue the experiment with the other two PEAbased polymers better compatible with h-ADASC colonization and survival in the long term in the in vitro previous results (Figure 3): PEA-HEA10 and PEA-AAc10. PEAAAc10 was also reselected because on PEA-HEA10 the collagen is adsorbed whereas in the PEA-AAc10 the collagen is covalently attached so the collagen conformation will be different in both surfaces, thus changing the cell adhesion domains exposure.

Six cases with macroporous PEA-HEA10 membranes (three with h-ADASCs and three without h-ADASCs), six cases with macroporous PEA-AAc10 membranes (three with h-ADASCs and three without h-ADASCs) and six control mock eyes were performed. The remaining six eyes were left untouched as additional control eyes.

3.5.1.2 PEA-AAc10 macroporous membranes. These macroporous membranes had a semitransparent appearance and generated a central opacity grade of 2 (T2) from the time of their implantation. Three cases of implant extrusion were observed (50\%); in the non extruded cases, the implant produced a marked anterior central protrusion (Table 
4). One week after implantation, all cases developed moderate and diffuse ocular inflammation associated with a progressive opacification of the implant, which became (when not extruded) completely opaque (T4) from the second month of monitoring, thereby precluding the visualization of any central intraocular structure. Severe diffuse neovascularization also developed, which involved most of the corneal surface (Figure 9F). One case of lipid keratopathy was detected. The ocular inflammation disappeared by the third month, excepted in one case in which it was persistent.

\begin{tabular}{|c|c|c|c|c|c|c|c|c|c|}
\hline \multirow[b]{3}{*}{ PEA Prosthesis ( $m: 30)$} & \multirow[b]{3}{*}{ Extrusion (\%) } & \multicolumn{8}{|c|}{ Cases Without Extrusion } \\
\hline & & \multicolumn{4}{|c|}{ Transparency (\%) } & \multicolumn{4}{|c|}{ Vascularization (\%) } \\
\hline & & 1 & 2 & 3 & 4 & 0 & 1 & 2 & 3 \\
\hline PEA & 78 & 50 & & & 50 & & & & 100 \\
\hline PEA + h-ADASC & 67 & 67 & & & 33 & 33 & 33 & & 33 \\
\hline PEA-AAc10 & 67 & & & & 100 & & & & 100 \\
\hline PEA-AAc10 + h-ADASC & 33 & & & & 100 & & & & 100 \\
\hline PEA-HEA10 & 0 & & & 100 & & 33 & & & 67 \\
\hline PEA-HEA10+ h-ADASC & 0 & & & 100 & & & & & 100 \\
\hline
\end{tabular}

Table 4. Clinical results of experimental eyes at the end of the follow-up. Corneal transparency (1: transparent but visible implant; 2: mild haze; 3: moderate haze; 4: severe opacification making it difficult to observe the eye's internal structures). Neovascularization (0: absence; 1: peripheral and mild; 2: peripheral and moderate; 3 : severe and affecting the central cornea).

3.5.1.3 PEA-HEA10 macroporous membranes. These macroporous membranes had a semitransparent appearance and generated a central opacity grade of 3 (T3) from the time of its implantation. Cases of implant extrusion or corneal ulceration were not observed during the entire follow-up (Table 4). Transparency remained stable in all cases during the entire follow-up without further opacification. The majority of cases (except for one case, Figure 9D), however, developed a superior, peripheral and moderate corneal neovascularization from the surgical incision, with a mild involvement of the central cornea (Figure 9E). The peripheral cornea remained intact and free from vessels and scars throughout the study. There was no clinically relevant ocular inflammation related to the implant.

Table 4 summarizes the clinical results of the 30 experimental cases at the time of euthanasia. All animals tolerated the procedure well despite a few complications. There were two cases of posterior perforation towards the anterior chamber ( $4.4 \%$ of pockets) and five cases of laceration of the anterior wall of the pocket (11\% of pockets). Differences in the extrusion rate between PEA and PEA-HEA10 were statistically 
J Biomed Mater Res Part A 2015:103A:1106-1118.

DOI: $10.1002 / \mathrm{jbm} . \mathrm{a} .35249$

significant $(\mathrm{p}=0.007)$. Differences in transparency and neovascularization were not statistically significant among the biomaterials. A slight reduction on the extrusion rate with the presence of h-ADASC was observed, but the differences were not statistically significant. No differences on transparency or vascularization with respect to the presence or absence of h-ADASCs were observed. The statistical analysis was performed with the non parametric Mann-Whitney test with Bonferroni modification.

\subsubsection{Histological analysis of transplanted corneas}

No relevant histological differences were observed among the biomaterials. In the cases of extrusion, there was no evidence of materials or cavities, and residual changes could be observed in their stroma: abundance of vessels and the presence of macrophages. Cases without implant extrusion presented an oval cavity in the central stroma $(5 \mathrm{~mm}$ in diameter and 300-600 $\mu \mathrm{m}$ in depth), which was partially occupied by the macroporous membrane, a $100 \mu \mathrm{m}$ thick chromophobe disc (Figure 10.1A/2A/3A). This central cavity occurred due to tissue dehiscence during the processing of the sample after fixation. A moderate macrophage response around the implant was observed, with isolated foreign body giant cells. The presence of an interface between the implanted material and the rabbit corneal tissues was also noted, which was composed of a strip of dense connective tissue surrounding the implant, with occasional inflammatory infiltrates, myofibroblast-like cells and neovessels, which were more abundant at the corners of the cavity (Figure 10.2B). These findings were more pronounced in the corneas with macroporous PEA-AAc10 membranes (Figure 10.3B). 




Figure 10. Histological sections of PEA (1A), PEA-HEA10 (2A,B) and PEA-AAc10: (3A,B) stained with Masson's trichrome (1A, 3A, 3B) and hematoxylin-eosin (2A, B). Macroporous membranes appear as chromophobe discs (1A, 2A, 3A. Macrophage reaction around the implant was observed to be more intense at the corners (2B, arrow) and with PEA-AAc10 (3B, arrows). A strip of dense connective tissue surrounding the implant is also observed (1A, 3A). 1A/2A/3A $100 \mathrm{X}$ magnification; 2B/3B 200X magnification.

\subsubsection{Presence of transplanted h-ADASCs by Vybrant CM-DiI fluorescence}

To evaluate whether h-ADASCs survived inside the rabbit cornea in vivo, Vybrant CMDil was monitored by epifluorescence microscopy. The eight corneas with non extruded colonized macroporous membranes presented cells strongly positive for CM-Dil distributed around the implant. Cells were present in low numbers independently of the PEA-based biomaterial (Figure 11). Vybrant CM-DiI was not detected in either of the negative controls or experimental eyes with uncellularized macroporous membranes. 




Figure 11. Fluorescence of Vybrant CM-DiI cells, 400X magnification (PEA: A; PEA-HEA10: B; PEAAAc10: C)

\section{DISCUSSION}

The purpose of this study was to evaluate macroporous PEA membranes (in vitro and in vivo) as possible scaffolds for enhanced keratoprosthesis, which could avoid the high rate of complications related to current treatment options that mainly use poly(methyl methacrylate (PMMA) or poly(2-hydroxyethyl methacrylate) (pHEMA) for their scaffolds $[1,3]$.

The glass transition temperature of PEA, which is well below body temperature, ensures that the material is in a rubber-like state and thereby pliable and flexible, with elastic modulus at the body temperature around $1 \mathrm{MPa}$ [18]. This value approximates to the module of the human corneas, that has a value between 0.3 and $3 \mathrm{MPa}$ [19]. PEA is, however, a fairly hydrophobic material, which raises questions about its performance inside the corneal stroma and the possibility of ulceration due to friction between the implant and host tissue. This friction could explain the high rate of corneal ulcers and implant extrusion (72\%) detected in cases in which the original PEA was implanted, and not because of a direct corneal stromal melt and inflammatory digestion. This is also supported by the fact that the PEA membranes did not generate a clinically relevant inflammation as did PEA-AAc10 during the postoperative period. Histological findings in non extruded cases with PEA membranes also support this theory by showing moderate macrophage response with only isolated foreign body giant cells but no actual melting of the surrounding tissue. This histiocytic reaction occurs mainly on the borders of the membrane, suggesting a certain amount of friction in those areas.

The introduction of hydrophilic units appears to be significant in the biointegration of the PEA prosthesis within the corneal stroma. Two types of these hydrophilic units have been considered in this study: hydroxyethyl acrylate (HEA) introduces hydroxyl groups at the surface of the material, while acrylic (AAc) or methacrylic (MAAc) acids 
introduce functional carboxyl groups. While HEA merely changes the surface tension, as shown by the significant decrease in WCA with low HEA content of the sample, AAc of MAAc units increase the wettability of the implant surface and enables protein binding [20,21]. A number of studies have proposed grafting carboxyl groups onto the surface of keratoprosthesis, which results in a significant increase in the attachment of biomaterial to the corneal tissue. Furthermore, the presence of carboxyl groups theoretically aids the immobilization of collagen on the surface by covalent bonds $[22,23]$. However, our results show that cell colonization decreases in the presence of high hydrophilicity (20\%), especially when the hydrophilic groups originate from AAc or MAAc (Figure 4B), and remains excellent in the presence of low hydrophilicity $(10 \%)$, but without significant differences compared with the original naked PEA.

PEA membranes have shown a favorable response to protein adsorption onto their surface. These proteins exhibit adhesion ligands that theoretically should improve adhesion of the cell to the surface of the implant. However, we could only demonstrate a significantly enhanced h-ADASC adhesion with the collagen-keratan sulfate covering when compared with the naked biomaterial. Fibronectin, peptide $\mathrm{FNIII}_{7-10}$, and collagen alone did not improve cell adhesion in our study.

For the in vivo assay, in addition to PEA, the two copolymers containing the lower amount of HEA and AAc -given that these biomaterials had the most favorable cell survival in vitro and optimal biophysical properties-, were implanted. Copolymers containing MAAc were discarded because they were opaque, biophysically unstable and less flexible than the other selected copolymers. Only six cases with the PEA-HEA10 and PEA-AAc10 groups were performed because this sample size was sufficient to demonstrate statistically significant differences in the implant extrusion rates between PEA (72 \%) and PEA-HEA10 (0 \%), with no differences between PEA and PEAAAc10 (50\%). Therefore, the low hydroxylation of PEA membranes significantly improved their survival in vivo.

Transplanting a cell substitute along with the structural support to undertake the critical functions in corneal homeostasis performed by keratocytes is essential because they produce factors such as collagen, proteoglycans, and metalloproteinases, which are indispensable for the health of the cornea and the long-term maintenance of corneal transparency [24]. To repopulate the scaffolds, h-ADASCs were used, which have been shown to be a perfect source of autologous stem cells for the development of 
J Biomed Mater Res Part A 2015:103A:1106-1118.

DOI: $10.1002 / j b m . a .35249$

tissue-engineered corneas and avoid the limitations of corneal cells $[6,8,25]$. Despite their demonstrated potential, no significant differences between the groups with or without h-ADASCs were found, with any improvement in the clinical or histological biointegration and implant extrusion rate. However, we were able to demonstrate that h-ADASCs survive at least three months in vivo when transplanted together with a PEA membrane. This lack of effect could be due to the low number of h-ADASCs. Efforts to increase cell numbers by promoting their survival or proliferation in vivo should be considered for future studies.

During the processing of the sample for histology, a cavity in the central stroma developed in all non extruded cases due to dehiscence between the biomaterial and the surrounding tissue. We believe that this is due to a lack of real integration of the biomaterial within the stroma. Therefore, despite the membrane's macroporous structure, neither the h-ADASCs nor the host keratocytes seem to infiltrate these membranes and generate new collagen inside them as initially expected. However, due to the normal quiescence of keratocytes, a follow-up of only three months could not be enough time to complete this process, so a longer follow-up might demonstrate a hostcell invasion of the porous implant with subsequent real biointegration of the PEA biomaterials into the surrounding stroma.

PEA membranes did not become fully transparent in vivo. This fact, however, is not relevant because these scaffolds are expected to remain inside the peripheral cornea, supporting a central lens with optical functions.

In conclusion, we report a new type of biomaterial that can be used as a scaffold for future keratoprosthesis. Although further research is warranted before their clinical application, we have demonstrated that the low hydroxylation of PEA membranes significantly improves their survival in vivo.

\section{ACKNOWLEDGEMENTS}

This work was supported in part by grants CEN-20091021 from the Spanish Ministry of Health, IAP-560610-2008-44 and SAF2010-19230 from the Spanish Ministry of Science and Innovation and from Fundació Marató de TV3, Spain. We would like to thank Fátima Domínguez (CEL) and Vissum ophthalmologists Felipe Soria Arrellano, Alessandro Abouda and Amr el Aswad for their technical help, IdiPAZ BioBank for sample custody, 
J Biomed Mater Res Part A 2015:103A:1106-1118.

DOI: $10.1002 / \mathrm{jbm} . \mathrm{a} .35249$

Biostatistics Section, La Paz Hospital for statistical analysis, and Juliette Siegfried (ServingMed.com) for the English editing of this manuscript.

\section{REFERENCES}

1. Aldave AJ et al. International results with the Boston type I keratoprosthesis. Ophthalmology 2012;119(8):1530-8.*

2. Tan A, Tan DT, Tan XW, Mehta JS. Osteo-odonto keratoprosthesis: systematic review of surgical outcomes and complication rates. Ocul Surf 2012;10(1):15-25.

3. Jirásková N, Rozsival P, Burova M, Kalfertova M. AlphaCor artificial cornea: clinical outcome. Eye 2011;25(9):1138-46.

4. Griffith $\mathrm{M}$ et al. Artificial human corneas: scaffolds for transplantation and host regeneration. Cornea 2002;21(7):54-61.**

5. Ruberti JW, Zieske JD. Prelude to corneal tissue engineering - gaining control of collagen organization. Prog Retin Eye Res 2008;27(5):549-77.**

6.- De Miguel MP, Alio JL, Arnalich-Montiel F, Fuentes-Julian S, de Benito-Llopis L, Amparo F, Bataille L. Cornea and ocular surface treatment. Curr Stem Cell Res Ther 2010;5(2):195-204.

7. Michelacci YM. Collagens and proteoglycans of the corneal extracellular matrix. Braz J Med Biol Res 2003;36:1037-1046.

8. Arnalich-Montiel F, Pastor S, Blazquez-Martinez A, Fernandez-Delgado J, Nistal M, Alio JL, De Miguel MP. Adipose-derived stem cells are a source for cell therapy of the corneal stroma. Stem Cells 2008;26(2):570-9.**

9. Espandar L, Bunnell B, Wang GY, Gregory P, McBride C, Moshirfar M. Adiposederived stem cells on hyaluronic acid-derived scaffold: a new horizon in bioengineered cornea. Arch Ophthalmol 2012;130(2):202-8. 
10. De Miguel MP, Fuentes-Julián S, Blázquez-Martínez A, Pascual CY, Aller MA, Arias J, Arnalich-Montiel F. Immunosuppressive properties of mesenchymal stem cells: advances and applications. Curr Mol Med 2012;12(5):574-91.*

11. Fang B, Song Y, Liao L, Zhang Y, Zhao RC. Favorable response to human adipose tissue-derived mesenchymal stem cells in steroid-refractory acute graft-versus-host disease. Transplant Proc 2007;39(10):3358-62 .

12. Puissant B et al. Immunomodulatory effect of human adipose tissue-derived adult stem cells: comparison with bone marrow mesenchymal stem cells. $\mathrm{Br} \mathrm{J}$ Haematol 2005;129(1):118-129.

13. Hilbig H, Kirsten M, Rupietta R, Graf HL, Thalhammer S, Strasser S, Armbruster FP. Implant surface coatings with bone sialoprotein, collagen, and fibronectin and their effects on cells derived from human maxillar bone. Eur $\mathrm{J}$ Med Res 2007;12(1):6-12.

14. Briz N, Antolinos-Turpin CM, Alió J, Garagorri N, Ribelles JL, Gómez-Tejedor JA. Fibronectin fixation on poly(ethyl acrylate)-based copolymers. J Biomed Mater Res B Appl Biomater 2013;101(6):991-7.

15. Zuk PA et al. Multilineage cells from human adipose tissue: Implications for cellbased therapies. Tissue Eng 2001;7:211-228.

16. Diego RB, Estellés JM, Sanz JA, García-Aznar JM, Sánchez MS. Polymer scaffolds with interconnected spherical pores and controlled architecture for tissue engineering: fabrication, mechanical properties, and finite element modeling. J Biomed Mater Res B Appl Biomater 2007;81(2):448-55.*

17. Li F, Griffith M, Li Z, Tanodekaew S, Sheardown H, Hakim M, Carlsson DJ. Recruitment of multiple cell lines by collagen-synthetic copolymer matrices in corneal regeneration. Biomaterials 2005; 26, 3093-3104.

18. Gallego Ferrer G, Salmerón Sánchez M, Gómez Ribelles JL, Romero Colomer FJ, Monleón Pradas M. Nanodomains in a hydrophilic-hydrophobic IPN based on poly(2-hydroxyethyl acrylate) and poly(ethyl acrylate). European Polymer Journal, 2007; 43, 3136-45. 
J Biomed Mater Res Part A 2015:103A:1106-1118.

DOI: $10.1002 / \mathrm{jbm} . \mathrm{a} .35249$

19. Jayasuriya AC, Ghosh S, Scheinbeim JI, Lubkin V, Bennett G, Kramer P, A study of piezoelectric and mechanical anisotropies of the human cornea, Biosens Bioelectron, 2003; 18, 381-7.

20. Alberto J, Campillo-Fernandez J, Pastor S, Abad-Collado M, Bataille L,. GomezRibelles JL, Meseguer-Dueñas JM, Monleon-Pradas M, Artola A, Alio JL, RuizMoreno JM. Future design of a new keratoprosthesis. Physical and biological analysis of polymeric substrates for epithelial cell growth. Biomacromolecules 2007; 8 (8), 2429-36.

21. Yang WT. Functionalized polylactide film surfaces via surface-initiated ATRP. Macromolecules 2011; 44: 2371-7.

22. Von Fischern T, Langefeld S, Yuan L, Völcker N, Reim M, Kirchhof B, Schrage NF. The "Aachen"keratoprosthesis: a new approach towards succesful keratoprosthesis-surgery. Int J Artif Organs 1999; 22(1): 52-7.

23. Kompa S, Langefeld S, Kirchhof B, Brenman K, Schrage N. AachenKeratoprosthesis as temporary implant. Case report on first clinical application. Int J Artif Organs 2000; 23(5):345-8.

24. Lynch AP, Ahearne M. Strategies for developing decellularized corneal scaffolds. Exp Eye Res 2013;108:42-7.

25. Martínez-Conesa EM, Espel E, Reina M, Casaroli-Marano RP. Characterization of ocular surface epithelial and progenitor cell markers in human adipose stromal cells derived from lipoaspirates. Invest Ophthalmol Vis Sci 2012;53(1):513-20. 